\title{
The use of extractable lipofuscin for age determination of crustaceans: Reply to Sheehy (2008)
}

\author{
H. Rodger Harvey ${ }^{1, *}$, David H. Secor ${ }^{1}$, Se-Jong Ju ${ }^{2}$ \\ ${ }^{1}$ University of Maryland Center for Environmental Science, Chesapeake Biological Laboratory, PO Box 38, Solomons, \\ Maryland 20688, USA \\ ${ }^{2}$ Marine Resources Research Dept., Korea Ocean \& Research Development Institute, Ansan PO Box 29, Seoul 425-600, \\ South Korea
}

\begin{abstract}
The heterogeneous mixture of metabolic by-products termed lipofuscin (LF) or age pigments has long been known to accumulate in post mitotic cells with increasing age. In crustaceans several approaches have been developed over the years to track LF accumulation and provide a proxy for chronological age. Histological approaches have been traditionally used for LF determination of crustaceans (e.g. Sheehy et al. 1994, Mar Biol 121:237-245), but over the last decade extraction approaches for neural tissues have been introduced (Ju et al. 1999, Mar Ecol Prog Ser 185:171-179) and tested (Ju et al. 2001, Mar Ecol Prog Ser 224:197-205; 2003, Fish Bull 101:312-320) for the crab Callinectes sapidis. In developing the extraction approach we have followed the most rigorous age validation steps available to us and carefully reported accuracy, precision, and bias estimates. In the present paper, we welcome the opportunity to respond to the individual concerns of Sheehy (2008, Mar Ecol Prog Ser 353:303-306) that (1) extractable LF remains unidentified, (2) extracted LF is not correlated with in situ LF, and (3) protein normalization does not produce a reliable assay. We argue that the fundamental issue of an incomplete characterization of LF as an ageing structure pervades most, if not all invertebrate fishery applications. We show positive correlation between the 2 methods, despite the lack of each to fully characterize the structurally complex products generated and sequestered in neural tissues. New information is presented on the ability of extractable LF to follow age in small macrozooplankton, suggesting the broad applicability of the extraction aging approach to small crustaceans. Dependent upon species and availability of known age animals for calibration, both histological and extraction approaches can be an effective method for age determination in crustaceans if they meet the requirements of validation, precision and bias estimations that typify rigorous age determinations in fisheries science.
\end{abstract}

KEY WORDS: Lipofuscin · Age determination · Age pigment · Crustaceans · Fisheries

Age determination is crucial in a number of biological disciplines, especially fisheries science. Over 8 yr ago, Ju et al. (1999) first presented a new approach to the aging problem in crustaceans, using lipofuscins extracted from neural tissues to estimate age of the blue crab Callinectes sapidus. The examination of lipofuscins (LF), or 'age pigments' as they are also called, was not in itself new; indeed these products have been observed and reported in the literature for well over 100 yr (Hannover 1842). Multiple approaches have been used over the years to follow the formation of this complex material in aging post mitotic cells, as well as the metabolic processes that lead to their accumulation and retention. Microscopic approaches were first used to observe these autofluorescent granules in mammalian neural tissues, and since that time histological 
analysis has been the primary approach in estimating their accumulation. An alternative approach presented in our original report (Ju et al. 1999), and tested in subsequent publications (Ju et al. 2001, 2003), validated the use of extractable LF to address the long-standing question of population age structure in crustaceans.

In an initial attempt to use histological dissection and microscopic observations in blue crab we found that we could estimate relatively few ages (brain tissue) or none at all (eye tissue encased in a chitinous sheath). This led us to concentrate on an alternative methodthe use of soluble LF. Our motivation for a more rapid biochemical approach should not be misconstrued as naiveté. In fact, the development and application of extractable LF measures from neural tissues was never intended to provide for the quantitative recovery of this polymeric material from tissues. As others noted in multiple publications, the collection of oxidized lipids and proteins which comprise cellular LF is both heterogeneous and largely uncharacterized (for review see Brunk \& Terman 2002), making its true concentration determination by any means open to debate. The lack of a fully defined mixture of products represented by neural LF, however, does not in itself discount the utility of either histological or biochemical approaches for their estimation. In our case, we tested the straightforward hypothesis that the accumulation of extractable LF in neural tissues during normal metabolism would allow a proxy for chronological age in blue crabs.

Should we be concerned that, regardless of the approach, investigators acknowledge they are making an incomplete measurement of a complex material with poorly understood chemical composition? In response, we note that virtually all age determination methods in fisheries science suffer the same constraint. For instance, we still lack a general explanation for yearly annulus formation in the scales and otoliths of fishes (Hoie \& Folkvord 2006) that occur in diverse temperate, tropical, freshwater, and deep-sea environments (Begg et al. 2005). Yet in countless instances, these structures support valid age determinations and important fishery stock assessments. Similarly, we only have a coarse understanding of why, and how, daily increments form in the otoliths of fish, yet daily ages are estimated in hundreds of applications across scores of species (Secor et al. 1995). This latter example is instructive: the initial controversy on the rate of 'microincrement' formation was not resolved through fundamental studies on the composition, or through mechanistic biomineralization studies, but rather by the dozens of studies that matched observed micro-increments in larval and juvenile fish to known ages (Jones 1992). Hypothetically, we can also consider the case in which crab size is highly correlated with age. Would we use size as an estimate of age in this instance?
Absolutely yes; despite an often mediocre correlation between size and age, length-based approaches remain a principal approach in crustacean stock assessment (Zheng et al. 1995). It seems clear that we should proceed with LF applications using alternative approaches as long as care is taken to verify the age determination and consider its accuracy and precision against the desired application.

Having said this, a mechanistically grounded approach that could be broadly applied across most crustacean (or fish) species would be revolutionary to fisheries science. Understandably, this is an important aspiration since LF formation is linked to physiological aging and senescence. From a more practical standpoint however, we can also consider LF as a cellular marker (i.e. an ageing structure) that can permit valid age determinations in specific applications regardless of underlying chemical makeup and formation processes. In fact, there is ample evidence that most crustacean LF investigators, rather than concerning themselves with structure and process, have moved aggressively to verify that LF measures correspond to age in population studies. Requisites in developing ageing approaches have been well reviewed in the fisheries literature (Beamish \& McFarlane 1983, Campana 2001), which emphasizes 3 important activities: (1) validation, (2) precision estimation, and (3) corroboration. In issues of validation and precision, we argue that the central objective is to determine whether the LF mixture can provide critical information on the age of an organism which is not possible otherwise. In that sense, information on the suite of complex structures involved is secondary.

Obtaining known-age individuals grown in wild or semi-wild conditions is one of the most rigorous methods for validating age estimates (Campana 2001), and is the approach we have followed (Ju et al. 1999, 2001, Puckett 2006) similar to others in the field (Sheehy et al. 1994, Belchier et al. 1998, Uglem et al. 2005). In recent work (Puckett 2006), we reared known-age hatchery crabs in outdoor ponds for $2 \mathrm{yr}$ periods and found strong correspondence between LF and age despite very different environmental histories (Fig. 1). The LF accumulation rate was nearly identical with past pond studies where initial ages of early instar crabs were assumed (Ju et al. 2001), providing evidence for the repeatability of the approach. Estimation of precision and resolution have been important objectives in our applications (Ju et al. 2001, Puckett 2006) because we hypothesized that most crabs recruited to fisheries at ages less than $1.5 \mathrm{yr}$.

Beyond crustaceans of economic importance, there is a need to better understand numerically important crustaceans which play functional roles in marine ecosystems. Although as adults the euphausiid Euphausia 

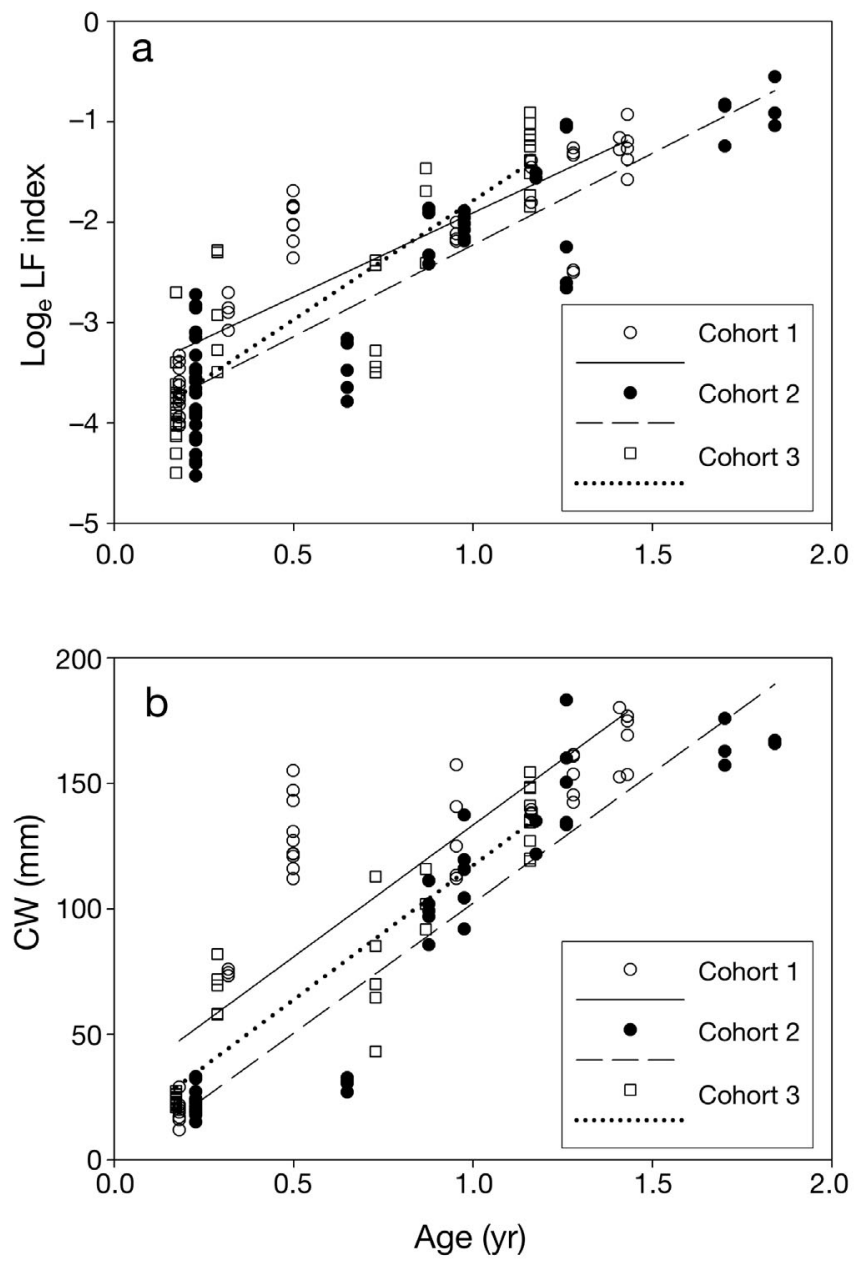

Fig. 1. Callinectes sapidis. (a) $\log _{\mathrm{e}}$ lipofuscin (LF index, $\mu \mathrm{g}$ $\mathrm{mg}^{-1}$ protein) and (b) carapace width (CW) (mm) accumulation as a function of age (yr) for 3 cohorts of known-age pondreared blue crabs $C$. sapidis (Cohort $1, \mathrm{n}=48$; Cohort $2, \mathrm{n}=$ 54; Cohort 3, $\mathrm{n}=40$ ). Solid, dashed, and dotted lines represent the best fitting linear regressions for Cohorts 1, 2, and 3, respectively. Data from Puckett (2006)

pacifica rarely exceed $25 \mathrm{~mm}$ (with correspondingly small brains), these krill and their relatives act as a central trophic linkage between primary producers and top predators in many marine systems. Information on euphausiid population structure and longevity is generally poorly understood, yet is essential in describing and modeling energy and carbon flow (Murphy et al. 1998). We have recently completed an age calibration for E. pacifica through laboratory rearing over 18 mo from eggs with results showing a strong positive correlation between age and extractable neural LF (Fig. 2; H. R. Harvey et al. unpubl.). While size alone provides a well-constrained measure over the first year until adulthood (Fig. 2b), LF accumulation continues after growth slows. This continued accumulation in instances of slowing or lack of growth is
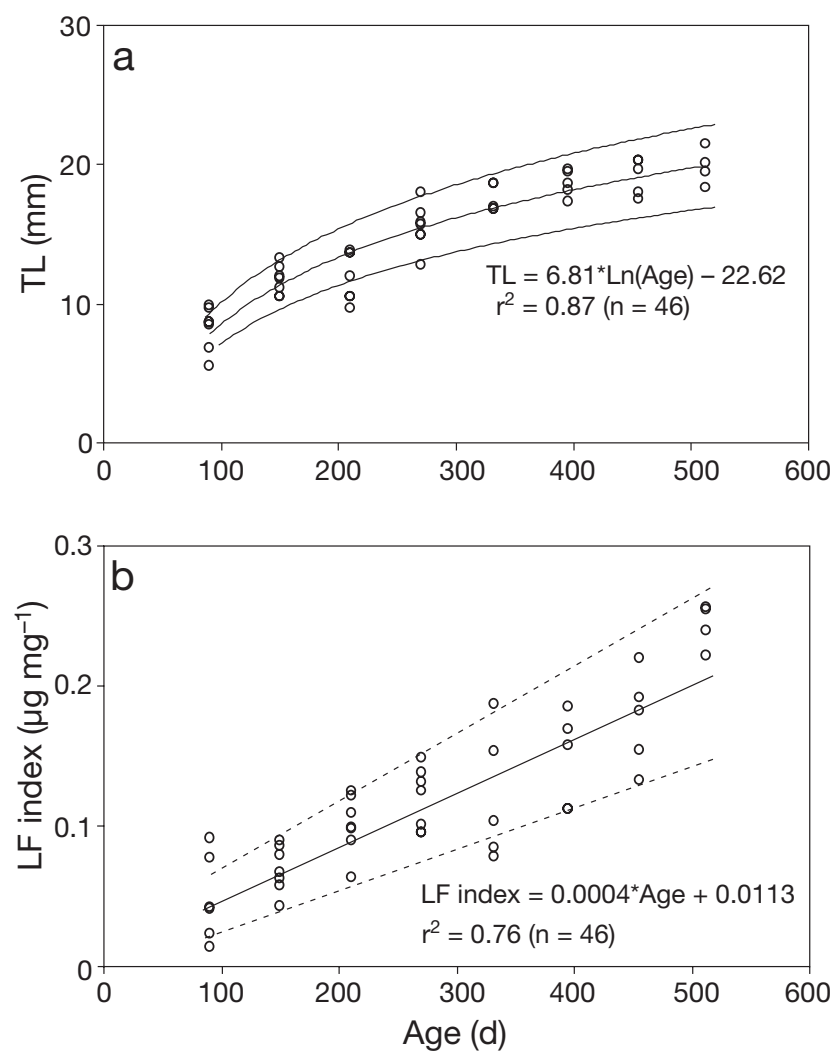

Fig. 2. Euphausia pacifica. (a) Size (total length, TL, in mm) increments and (b) extractable lipofuscin (LF) accumulation of the known-age krill E. pacifica raised from eggs in the laboratory. Lines, equations, and $\mathrm{r}^{2}$ values were obtained from regression analysis using all values. 95\% CI for each regression are shown as dashed lines. Data from H. R. Harvey et al. (unpubl.) with permission

where biochemical proxies such as LF, whether determined through histological or extractable approaches, have the potential for important contributions towards understanding crustacean population demographics.

Despite dedicated early efforts, we have not yet rigorously corroborated extraction- and histologicalbased methods. Due to the difficulty in observing LF granules in the optic nerve (O. Tully pers. comm.), our early efforts compared granule densities in the brain as is typically conducted with the soluble LF of the optic nerve. For the same individual crabs, we did observe a positive correspondence between the 2 approaches (Fig. 3; Ju 2000). Confocal microscopy has recently shown promising results (Kodama et al. 2006) and might permit future tests of corroboration between the 2 approaches. We do wish to emphasize here, however, that corroboration does not address the validity of a particular age determination approach, it only provides a comparison between methodologies that need not be 'directly or logically linked' (Campana 2001, p. 216). In this regard, we did corroborate our results 


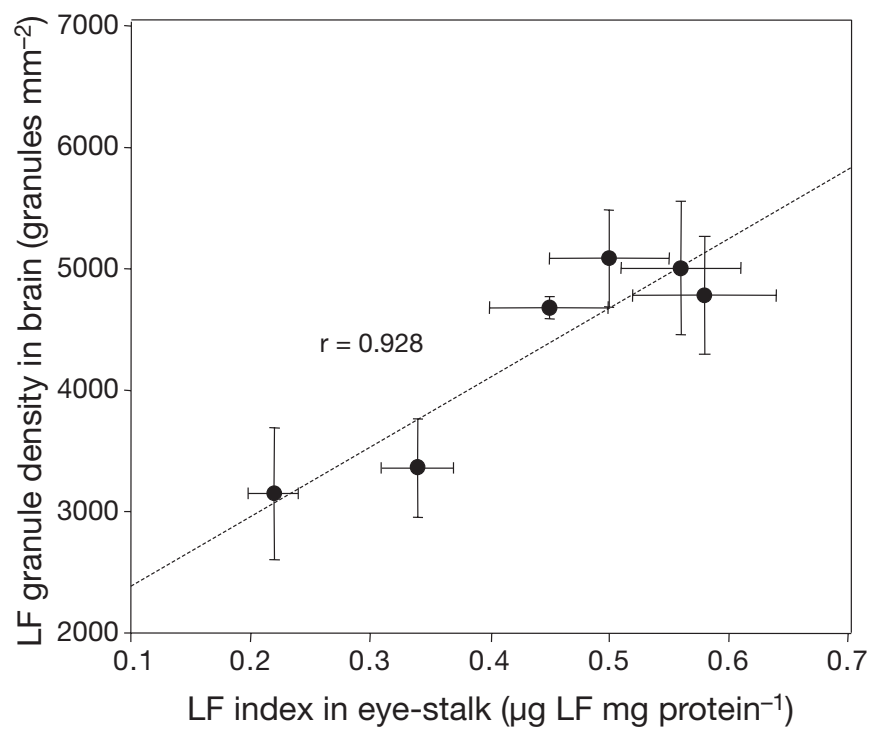

Fig. 3. Callinectes sapidis. Lipofuscin (LF) index in eyestalk versus lipofuscin granule density in brain tissue from the same individual crabs. Error bars: $2 \mathrm{SD}(\mathrm{n}=3$ to 5 ). $\mathrm{r}$ is based on least squares analysis of the means. For histological analysis, methods of Sheehy (1990) were used for fixation and processing of brain tissue. Ten sections were prepared for each brain tissue, with 4 to $6 \mu \mathrm{m}$ deroal sections obtained.Taken from Ju (2000)

against those of size-based assessments for blue crabs and found consistency between the two (Ju et al. 2003, Puckett 2006). Indeed, the most recent blue crab assessment incorporated findings from our LF-based age determinations (Miller et al. 2005).

Could correspondence between LF and age be a palimpsest underlain by a relationship between LF and size? This concern has a long history in fisheries science, where D'Arcy Thompson was convinced that year-classes of Norwegian herring (determined by annuli in scales) were chiefly the result of size differences in sampled shoals; that a relationship between phenotypic modes of annuli and age was statistically unlikely (Thompson 1914, Smith 1994). We gave this due consideration early in our work and have several lines of evidence against this. In field collections (1) LF and carapace width (CW) are poorly correlated in crab and krill field samples $\left(\mathrm{r}^{2}<0.42\right.$; Ju et al. 1999, 2003); and (2) we observed increased resolution in the number and separation of modes of LF in comparison to CW modes (Ju et al. 1999, 2003). Furthermore, in pond rearing studies of known-age crabs, (1) LF was associated with age in a similar manner despite very different growth histories (Fig. 1; Ju et al. 2001); and (2) LF continued to accumulate during winter months, despite cessation of somatic growth (Ju et al. 2001).

The concern expressed by Sheehy (2008) over protein normalization and its reliability is an interesting question, and again one in which the history of LF esti- mation is a useful guide. The determination of cellular constituents, enzymatic activities and specific synthesis processes has long relied on total protein as a primary method of standardization. This has also included widely used methods for monitoring the oxidative damage to proteins seen as carbonyl derivatives (Buss et al. 1997) and important observations of declining proteolytic activity in postmitotic cells (Grune et al. 2005), both of which provide mechanistic clues to LF formation. Given that a major constituent of LF is clearly oxidized proteins, we would argue that it makes implicit sense to normalize its accumulation to a primary cellular starting material consistent with the vast majority of studies of cellular function and activity. In addition, the normalization of LF concentration to the extracted tissue has practical advantages to the analyst, including the ability to determine LF and protein content from the same sample, and the avoidance of the additional handling required for alternative approaches (e.g. tissue weight). In the case of our work with the blue crab, the presence of the chitinous sheath surrounding the eyestalks was a practical problem; it accounts for a significant mass of the dissected tissue but contributes nothing to LF formation. Indeed, despite concerted efforts for histological comparisons, this sheath was also a physical impediment to clean dissection and mounting of eyestalks for histological sections (O. Tully pers. comm.). Using tissue protein as the metric for comparison, however, provided a reliable measure in our hands. We are hopeful others will find it as useful.

Acknowledgements. We thank the Chesapeake Bay NOAA Office, Maryland Sea Grant and NSF Biological Oceanography for support of our past LF applications. S.J.J. received partial support from KORDI (PP07401) and the researcher invitation program sponsored by KORP. This is contribution 4146 of the University of Maryland Center for Environmental Science.

\section{LITERATURE CITED}

Beamish RJ, McFarlane GA (1983) The forgotten requirement of age validation in fisheries biology. Trans Am Fish Soc 112:35-743

Begg GA, Campana SE, Fowler AJ, Suthers IM (2005) Otolith research and application: current directions in innovation and implementation. Mar Freshw Res 56:477-483

Belchier M, Edsman L, Sheehy MJR, Shelton PMJ (1998) Estimating age and growth in long-lived temperate freshwater crayfish using lipofuscin. Freshw Biol 39:439-446

Brunk UT, Terman A (2002) Lipofuscin: mechanisms of agerelated accumulation and influence on cell functions. Free Radic Biol Med 33:611-619

Buss H, Chan TP, Sluis KB, Domigan NM, Winterbourn CC (1997) Protein carbonyl measurement by a sensitive ELISA method. Free Radic Biol Med 23:361-366

Campana SE (2001) Accuracy, precision and quality control in age determination, including a review of the use and abuse of age validation methods. J Fish Biol 59:197-242 
Grune T, Merker K, Jung T, Sitte N, Davies KJA (2005) Protein oxidation and degradation during postmitotic senescence. Free Radic Biol Med 39:1208-1215

Hannover A (1842) Mikroskopische Undersolgeser af Nervensystemet. K Dan Vidensk Selsk Skr Nat Math Afd 10:1-112 (in Danish)

Hoie H, Folkvord A (2006) Estimating the timing of growth rings in Atlantic cod otoliths using stable oxygen isotopes. J Fish Biol 68:826-837

Jones CM (1992) Development and application of the otolith increment technique. In: Stevenson DK, Campana SE (eds) Otolith microstructure examination and analysis. Can Spec Publ Fish Aquat Sci 117:1-11

Ju SJ (2000) Development and application of biochemical approaches for understanding age and growth in crustaceans. PhD thesis, University of Maryland College Park, College Park, MD

Ju SJ, Secor DH, Harvey HR (1999) Use of extractable lipofuscin for age determination of blue crab Callinectes sapidus. Mar Ecol Prog Ser 185:171-179

Ju SJ, Secor DH, Harvey HR (2001) Growth rate variability and lipofuscin accumulation rates in the blue crab Callinectes sapidus. Mar Ecol Prog Ser 224:197-205

Ju SJ, Secor DH, Harvey HR (2003) Demographic assessment of the blue crab (Callinectes sapidus) in Chesapeake Bay using extractable lipofuscins as age markers. Fish Bull (Wash DC) 101:312-320

Kodama K, Shiraishi H, Morita M, Horiguchi T (2006) Verification of lipofuscin-based crustacean ageing: seasonality of lipofuscin accumulation in the stomatopod Oratosquilla oratoria in relation to water temperature. Mar Biol 150: 131-140

Miller TJ, Martell SJD, Bunnell DB, Davis G and others (2005) Stock assessment of blue crab in Chesapeake Bay. NOAA Chesapeake Bay Office, Annapolis, MD

Murphy EJ, Watkins JL, Reid K, Trathan PN and others (1998) Inter-annual variability of the South Georgia marine

Editorial responsibility: Matthias Seaman (Assistant Editorin-Chief), Oldendorf/Luhe, Germany ecosystem: biological and physical sources of variation in the abundance of krill. Fish Oceanogr 7:381-390

Puckett BJ (2006) Growth and recruitment rates of juvenile blue crabs (Callinectes sapidus) in Chesapeake Bay. MSc thesis, University of Maryland College Park, College Park, MD

Secor DH, Dean JM, Campana SE (1995) Fish otoliths: faithful biological and environmental chronometers? In: Secor DH, Campana SE, Dean JM (eds) Recent developments in fish otolith research. Belle W. Baruch Library in Marine Sciences, No. 19. University of South Carolina Press, Columbia, SC, p xxv-xxvii

Sheehy MRJ (1990) Individual variation in, and the effect of rearing temperature and body size on, the concentration of fluorescent morphological lipofuscin in the brains of freshwater crayfish, Cherax cuspidatus (Crustaces: Parastacidae). Comp Biochem Physiol 96A:281-286

Sheehy MRJ (2008) Questioning the use of biochemical extraction to measure lipofuscin for age determination of crabs: Comment on Ju et al. (1999, 2001). Mar Ecol Prog Ser 353:303-306

Sheehy MRJ, Greenwood JG, Fielder DR (1994) More accurate chronological age determination of crustaceans from field situations using the physiological age marker, lipofuscin. Mar Biol 121:237-245

Smith TD (1994) Scaling fisheries: the science of measuring the effects of fishing, 1855-1955. Cambridge University Press, Cambridge

Thompson DW (1914) The age of herring. Nature 94:60-61

Uglem I, Belchier M, Svasand T (2005) Age determination of European lobsters (Homarus gammarus L.) by histological quantification of lipofuscin. J Crustac Biol 25: 95-99

Zheng J, Murphy MC, Kruse GH (1995) A length-based population-model and stock-recruitment relationships for red king crab, Paralithodes camtschaticus, in Bristol Bay, Alaska. Can J Fish Aquat Sci 52:1229-1246

Submitted: November 26, 2007; Accepted: November 29, 2007 Proofs received from author(s): December 17, 2007 